\title{
Review Article \\ Strongyloidiasis Current Status with Emphasis in Diagnosis and Drug Research
}

\author{
Tiago Mendes, Karen Minori, Marlene Ueta, \\ Danilo Ciccone Miguel, and Silmara Marques Allegretti
}

Department of Animal Biology, Post-Graduation Program in Animal Biology, Institute of Biology, University of Campinas (UNICAMP), Campinas, SP, Brazil

Correspondence should be addressed to Danilo Ciccone Miguel; dcmiguel@unicamp.br and Silmara Marques Allegretti; sallegre@unicamp.br

Received 25 October 2016; Accepted 8 December 2016; Published 22 January 2017

Academic Editor: D. S. Lindsay

Copyright (C) 2017 Tiago Mendes et al. This is an open access article distributed under the Creative Commons Attribution License, which permits unrestricted use, distribution, and reproduction in any medium, provided the original work is properly cited.

\begin{abstract}
Strongyloidiasis is a parasitic neglected disease caused by the nematode Strongyloides stercoralis affecting 30 to 100 million people worldwide. Complications, strongly associated with alcoholism, organ transplants, and HTLV-1 virus, often arise due to late diagnosis, frequently leading to patient death. Lack of preemptive diagnosis is not the only difficulty when dealing with this parasite, since there are no gold standard diagnostic techniques, and the ones used have problems associated with sensitivity, resulting in false negatives. Treatment is also an issue as ivermectin and benzimidazoles administration leads to inconsistent cure rates and several side effects. Researching new anti-Strongyloides drugs is a difficult task since S. stercoralis does not develop until the adult stages in Mus musculus (with the exception of SCID mice), the main experimental host model. Fortunately, alternative parasite models can be used, namely, Strongyloides ratti and S. venezuelensis. However, even with these models, there are other complications in finding new drugs, which are associated with specific in vitro assay protocol steps, such as larvae decontamination. In this review, we highlight the challenges associated with new drug search, the compounds tested, and a list of published in vitro assay methodologies. We also point out advances being made in strongyloidiasis diagnosis so far.
\end{abstract}

\section{Introduction}

Strongyloidiasis, caused by nematode parasites of the genus Strongyloides, is a cosmopolitan neglected disease with high prevalence in Caribe, Latin America, Europe, Asia, and sub-Saharan Africa [1]. In Humans, Strongyloides stercoralis, which can also parasite other mammals such as dogs or cats, is the predominant species $[2,3]$. An estimated 30 to 100 million people are infected worldwide, though it is believed that this number is underestimated due to inappropriate or low sensitivity diagnostic techniques [3].

Several studies have been published using murine models focusing in immunodiagnostic or in the host immune response, in an attempt to understand immunological aspects that are still unknown [4-10]. Immunosuppression has been correlated with the infection aggravation, mainly in cases of HTLV-1 virus coinfection, alcoholism, and corticoids use [1114]. Understanding the parasite behavior in this particular context will allow not only the research and development of better therapeutic options but also better diagnostic methodologies that could lead to detection of lower parasite burden infections, allowing patients to be treated before their health deteriorates.

Ivermectin is the drug of choice against S. stercoralis; however, its use is restricted in several countries, and a consensus, regarding how many dosages should be given or the time between each dosage, has not been reached. Ivermectin also shows irregular cure rates, varying between 55 and 100\% in immunocompetent patients [29-31]. Other drugs, such as albendazole (cure rates between 38 and $87 \%$ ) and its analogues have also been used, with thiabendazole being the most commonly used, with cure rates between 52 and $100 \%$, though its use may cause side effects such as nausea, vomit, anorexia, asthenia, and diarrhea along with neurologic effects such has dizziness, sleepiness, and disorientation, making its use discouraged by health professionals $[29,31]$. 
In this review, we highlight the need to develop new diagnostic techniques with higher sensitivity and the importance of mandatory S. stercoralis screening not only for organ donors and receivers but also for immunosuppressed patients in general. Besides, more efficient treatment strategies are lacking as options for the management of the strongyloidiasis patient, requiring the establishment of more adequate dosages and the research of new drugs/drug formulations. Then, a list of the drugs being searched and the methodologies employed are summarized in the present review.

\section{S. stercoralis Immunosuppression and Diagnosis}

HTLV-1 is a RNA retrovirus belonging to the Retroviridae family prevailing in Japan, sub-Saharan Africa, Melanesia, Middle East, and South America. Associated with T-cell lymphoma, HTLV-1 has been correlated with S. stercoralis infection since it depresses the host's immune system allowing the parasite to establish the infection [32-37].

Upon entering T-cells, the lymphotropic virus intensifies cell production, generating an exacerbated Thl response, with high levels of INF- $\gamma$, TNF- $\beta$, and IL-2, along with a decline in IL-4, IL-5, and IL-10 production [38, 39]. Viral-caused immunosuppression promotes massive S. stercoralis infections, making treatment difficult due to parasite dissemination. Among reported cases, the most common symptomatology associated with this coinfection consists in vomits, diarrhea, weight loss, cough, and, in some cases, larvae and/or adult females can be found in sputum [14, 32$36,39,40]$.

Alcoholism is also associated with S. stercoralis infections $[13,41]$. Ethanol depresses the immune system and, when excessively consumed, causes behavioral changes, which can further expose an already impaired host to infections [41]. In a paper published by Silva et al. [13], S. stercoralis infection prevalence was higher in alcoholic patients (23.5\%) than in nonalcoholic ones (5.4\%). Among the alcoholic patients, $81.3 \%$ presented high parasite loads, suggesting that high cortisol levels, commonly associated with alcoholism, may lead to massive infections. Increase in ethanol levels leads to an increase in corticosteroids, reducing T-cells function and increasing S. stercoralis females fertility [13], alerting that not only alcoholic patients but also patients requiring corticosteroids use are at risk.

There are several reported cases of organ-receiving patients, with daily corticosteroids use, suffering complications due to $S$. stercoralis infection, often leading to their death [42-56]. Usually, in transplanted patients, strongyloidiasis diagnosis is only revealed after complications appear, pointing to a need of preemptive diagnosis before the transplant, not only of the recipient, but also of the donor, since cases of passage through infected organs have been described [57]. In a paper publish by Luvira et al. [58] with 135 immunocompromised patients, using 3 diagnostic techniques, 8 were infected with S. stercoralis, where Strongyloides IgG detection through indirect enzyme-linked immunosorbent assay (ELISA) only showed a $42,9 \%$ sensitivity. Steinmann et al. [59] also observed that, in cases where treatment failed but parasite load reduced, the diagnostic tests often failed to detect remaining parasites, showing a requirement for more sensitive tests.

Due to S. stercoralis ability to autoinfect the host, only complete cure eliminates the risk of future complications; therefore, it is mandatory to employ accurate diagnostic methodologies capable of detecting light and mild infections [60]. Currently, there is no gold standard diagnostic technique for S. stercoralis [61, 62]. Routine diagnosis usually consists of parasitological and/or serological methods, though their performance is far from great [60]. Several parasitological tests have been used to detect larvae in stool samples, including Baermann method, formalin-ethyl acetate, Harada-Mori culture, and Agar Plate Culture (ACP); however, these tests have low sensitivity (21 to $89 \%$ ) due to low parasite load and irregular larvae elimination, making it necessary to collect several stool samples throughout several days $[7,60,63]$. Among these methods, ACP is considered the most efficient but also the most laborious one, taking 2 to 3 days, requiring fresh stool samples and an experienced technician [7, 63-65].

Several immunologic techniques have been studied, including enzyme-linked immunosorbent assay (ELISA), indirect agglutination, indirect immunofluorescence, and western blot, all with different sensitivities and specificities, depending on the antigen and isotopic antiglobulin preparation $[6,9,66-78]$. Immunologic methods show a higher sensitivity than the conventional parasitological ones; nevertheless, there are concerns with its specificity due to cross-reactions with other $[6,67,68]$ helminthes and with false positives due to antibody persistence. Although there are concerns regarding immunologic tests specificity, some works have shown promising results in the use of in-house indirect immunofluorescence antibody test (IFAT) (sensitivity $97 \%$; specificity $\sim 100 \%$ ) or ELISA (sensitivity $>97 \%$; specificity 100\%) $[60,72,79]$. Even so, further studies are needed to optimize their use. It should also be noticed that, in immunosuppressed patients, immunodiagnosis can be tricky, due to reduced sensitivity of serum antibody detection, where the more immunocompromised the patient, the lower the sensitivity $[60,80]$. Serological and epidemiological studies based on the diagnosis of human strongyloidiasis usually use both serology and stool culture, while some researchers have started to use PCR (conventional or not), though not so frequently [80].

Among diagnostic techniques, the utilization of polymerase chain reaction (PCR) (conventional PCR (cPCR), nested-PCR, or real-time-PCR (qPCR)) [7, 8, 62, 79-91] has been considered as a valuable method. PCR methodologies show superior sensitivity when compared with parasitological or immunological methods even studies indicating that sensitivity can vary, possibly as a result of the extraction method [7, 62, 79, 80, 82, 86, 88, 89]. Thus, optimizing and standardizing DNA extraction methodology are extremely important to increase molecular diagnostic sensitivity.

QPCR-based diagnosis has been more often applied, showing high sensitivity and specificity. Its use may represent a decrease in the amount of time needed for a diagnosis and also increase the parasite detection success, being used not 
only for fecal samples but also for cerebrospinal fluid samples from patients with Strongyloides associated meningitis [8, $62,75,79,83,84,87,88,91]$. Currently, qPCR is the most exploited molecular method due to its higher sensitivity comparing to cPCR (sensitivity $76,7 \%$; specificity $84,3 \%$ ) [84], but it also presents higher costs than the ones associated with cPCR. Sharifdini et al. [62] found a higher sensitivity in nested-PCR (sensitivity 100\%, specificity $91.6 \%$ ) compared to qPCR (sensitivity $84.7 \%$, specificity $95.8 \%$ ), representing a possible alternative with lower costs.

Better diagnostic tools for S. stercoralis infections are needed. Parasitological methods show an unsatisfactory sensitivity, even when APC is performed and although serological diagnosis shows a good sensitivity, there are several concerns regarding cross-reactions $[6,7,60,67-73,75,76]$. Molecular diagnosis can be considered a promising tool that has been employed in some research and clinical laboratories, but with no standardized methodology so far $[12,40,92-$ 95]. Optimization of S. stercoralis diagnostic is certainly a crucial step in the fight against strongyloidiasis, so that future complications and/or fatalities caused by this parasite may be avoided.

\section{Models for Strongyloides Infection in Preclinical Investigation and Drug Research}

Treating Strongyloides infection represents a major challenge. Ivermectin is the most effective drug against $S$. stercoralis; however, it is not licensed in several countries and the treatment regimen still needs to be better assessed [29, 30]. Although albendazole and other benzimidazoles can be used as alternatives, their efficiency is inferior to ivermectin [30], showing an imperative need in investing and finding alternative anti-Strongyloides drugs.

Historically, Mus musculus mouse has been the most commonly used model to understand basic biology and diseases in Biomedical Research. Nevertheless, mice and rats are not susceptible to $S$. stercoralis infection [2, 96-98] since larvae penetrate the skin and migrate to the lungs, moving towards skeletal muscle, not being able to promote a patent infection or not even reaching the intestines, therefore making it impossible to maintain the parasite and quite challenging to be used in the laboratory routine $[2,97,99]$. It is interesting to note that, just like in immunocompetent mice, in nude mice (T-cell deficient), S. stercoralis does not reach maturity in the small intestine. However, in SCID mice (T- and B-cell deficient), the entire $S$. stercoralis cycle can be reproduced, though their high cost and special needs due to a compromised immune system limit its use [96].

Strongyloides ratti, a rat parasite, was the first alternative model to be used as a research tool in strongyloidiasis and, years later, Strongyloides venezuelensis was also acknowledged as suitable model for this disease. Although there are some limitations in utilizing infections by these species, mainly due to the absence of autoinfection (present in S. stercoralis), $S$. ratti and $S$. venezuelensis naturally infect rodents and also possess an endogenous and exogenous cycle, being important models to understand strongyloidiasis biology and immunology and in searching for new drug alternatives against Strongyloides [100-103].

Dogs and primates are naturally infected with S. stercoralis [104]. Up until the 90s, due to the lack of rodent models, most laboratories used them as experimental S. stercoralis hosts, studying the parasite biology and immunology [19]. Even though nowadays some laboratories still use them whether for parasite maintenance or laboratory experiments $[18,104]$, their use has decreased when Nolan et al. [23] published a work, proving that gerbils (Meriones unguiculatus) were able to develop a chronic infection similar to that observed in humans. Gerbils develop long course infections ( 130 days) and autoinfection can be induced with steroid treatment, leading to massive hyperinfection, usually associated with human immunosuppression, making the gerbil an important model to study many biological and immunological aspects of the host-parasite interaction $[18,19$, 23].

When researching new anti-Strongyloides candidates, some requirements need to be considered in order to ensure the quality of the infection, as the use of decontaminated larvae, which may be a challenge since they are obtained from feces [15]. Given the importance of larvae decontamination for the infection procedure, protocols regarding this step are summarized in Table 1.

The same can be mentioned for in vitro compound and drug testing assays. Currently, few anti-Strongyloides new drug research papers have been published; however, considering the small number, there is a great diversity of protocols used. Parameters evaluated in these papers include larvae survival, determined by parasite movement, and egg hatching (Table 2) [16, 17, 22, 24, 25]. A few research groups showed promising in vitro results, as the activity of 2 (butylamino)hexadecan-1-ol, Newbouldia laevis essential oil, and Zanthoxylum zanthoxyloides essential oil against $S$. ratti and S. venezuelensis or Eryngium foetidum crude extract and Eryngial (trans-2-dodecenal) against S. stercoralis $[16$, $21,22]$ (Table 3). On the other hand, in vivo published data (summarized in Table 4) do not necessarily support results obtained in vitro. For example, in a study conducted by Legarda-Ceballos et al. [16], out of four compounds with promising in vitro results, only one was capable of reducing mice parasite load in $\sim 60 \%$. Compounds derived from Piper tuberculatum, with known insecticide, trypanocidal, and fungicidal action, and compounds derived from Lippia sidoides, effective against some bacteria and Aedes aegypti larvae, were ineffective against $S$. venezuelensis in vivo. Monepantel (AAD 1566), which has been used as an anthelminthic in veterinary medicine, was inefficient against S. ratti in vivo $[27,28]$. Tribendimidine showed efficiency against $S$. ratti in vivo when applied in a single dosage of $50 \mathrm{mg} / \mathrm{kg} 72 \mathrm{~h}$ after infection, reducing the infection in $98.9 \%$ [17]; however, when used in a clinical trial, in a population infected with $S$. stercoralis, cure rates dropped by $54,5 \%$ [105]. Taking the data summarized into consideration, it is evident that laboratorial parasite models are extremely important although some limitations may arise when crossing over to $S$. stercoralis. An alternative to reduce these obstacles would be the use of gerbil (Meriones unguiculatus), 


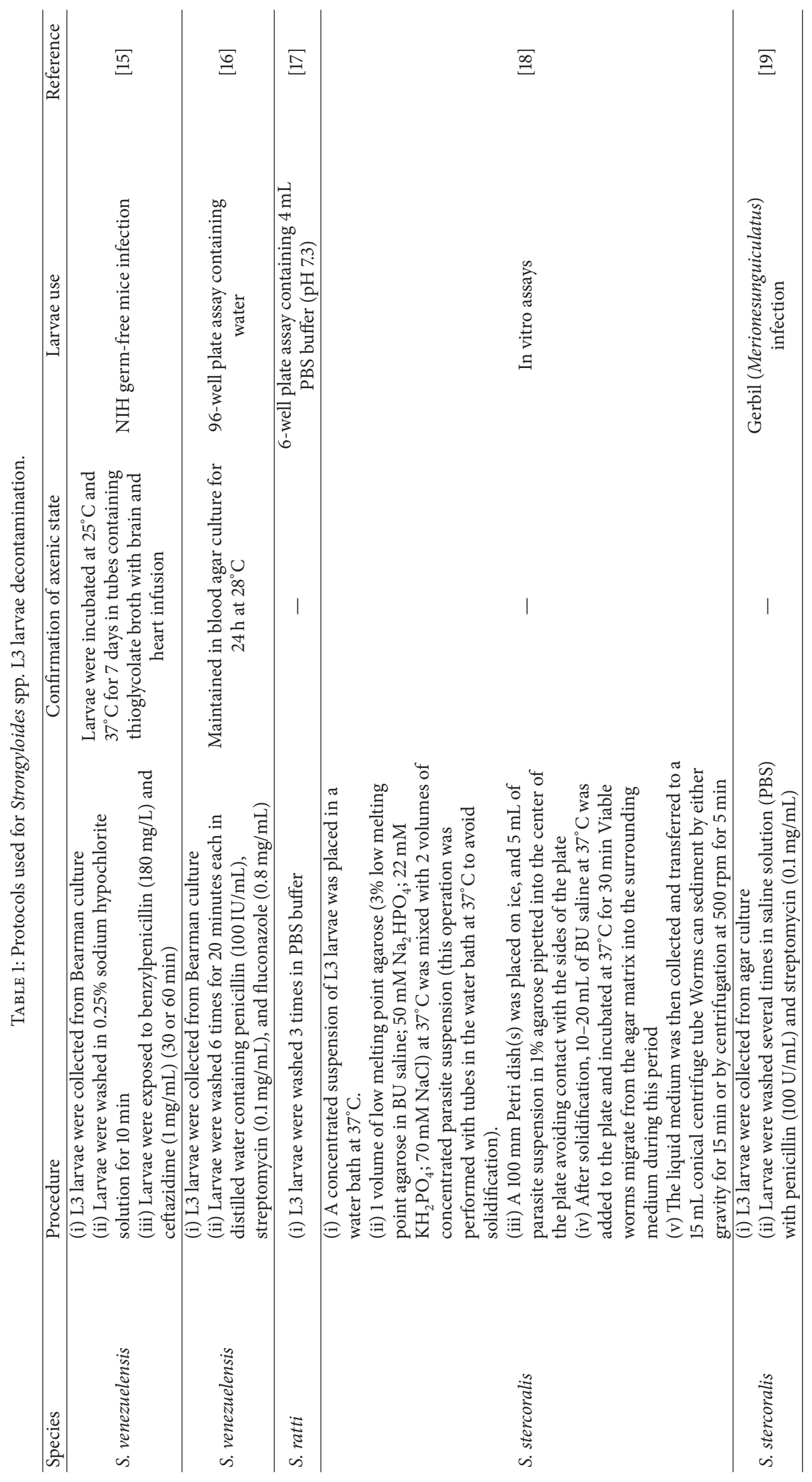




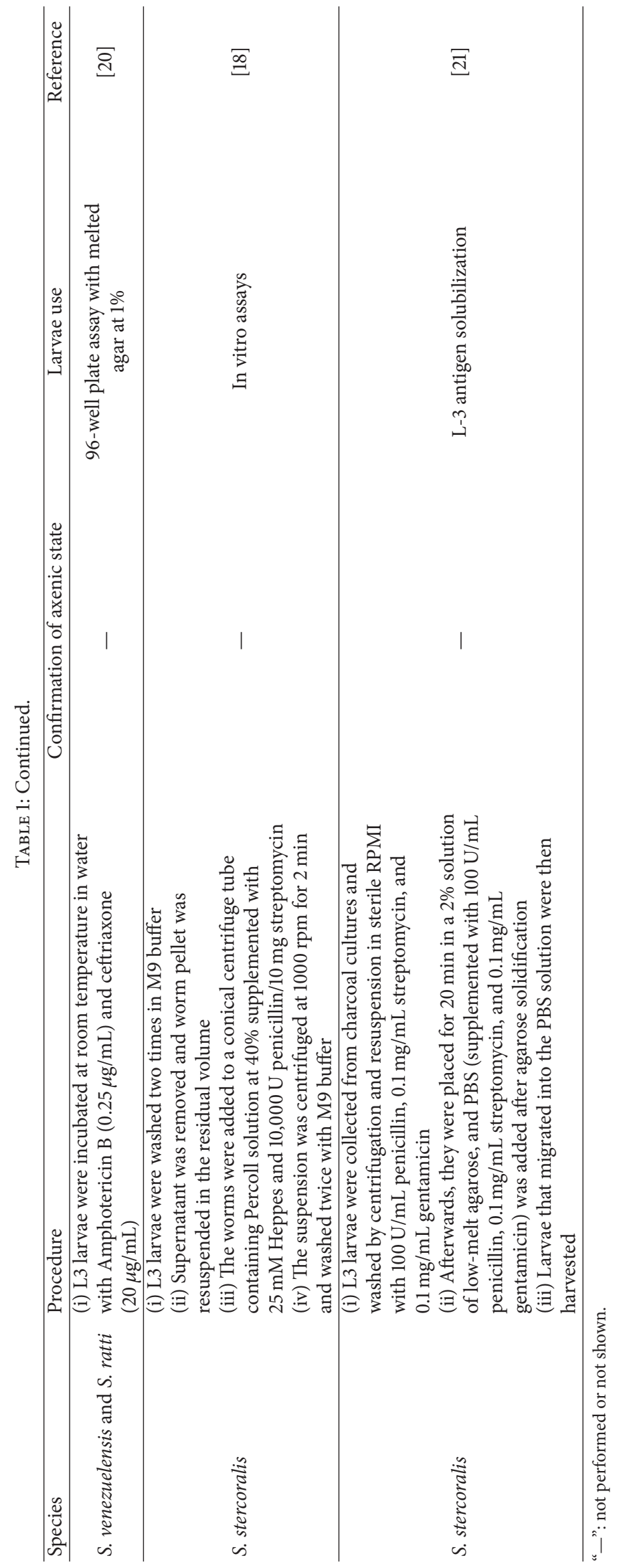




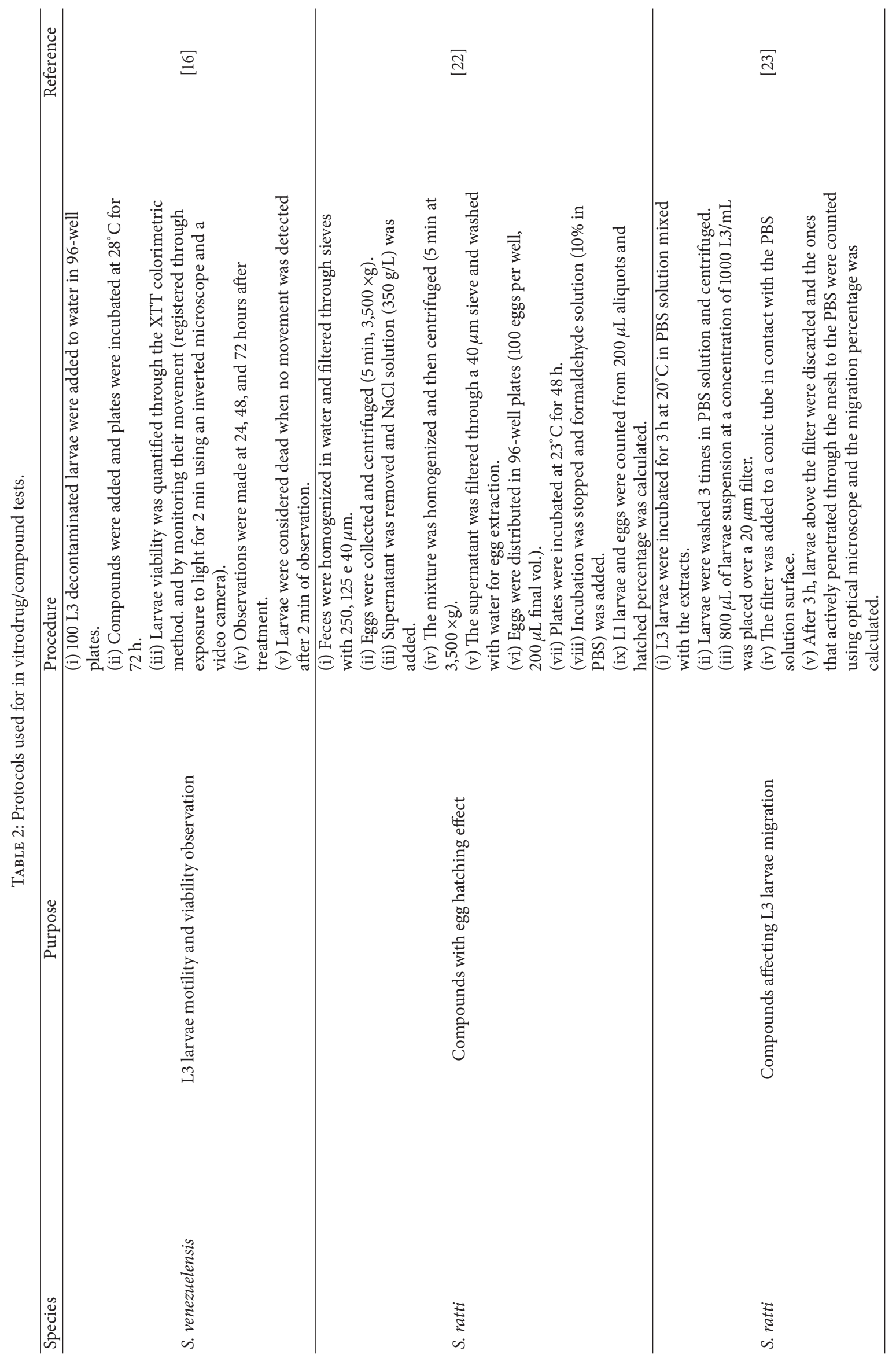




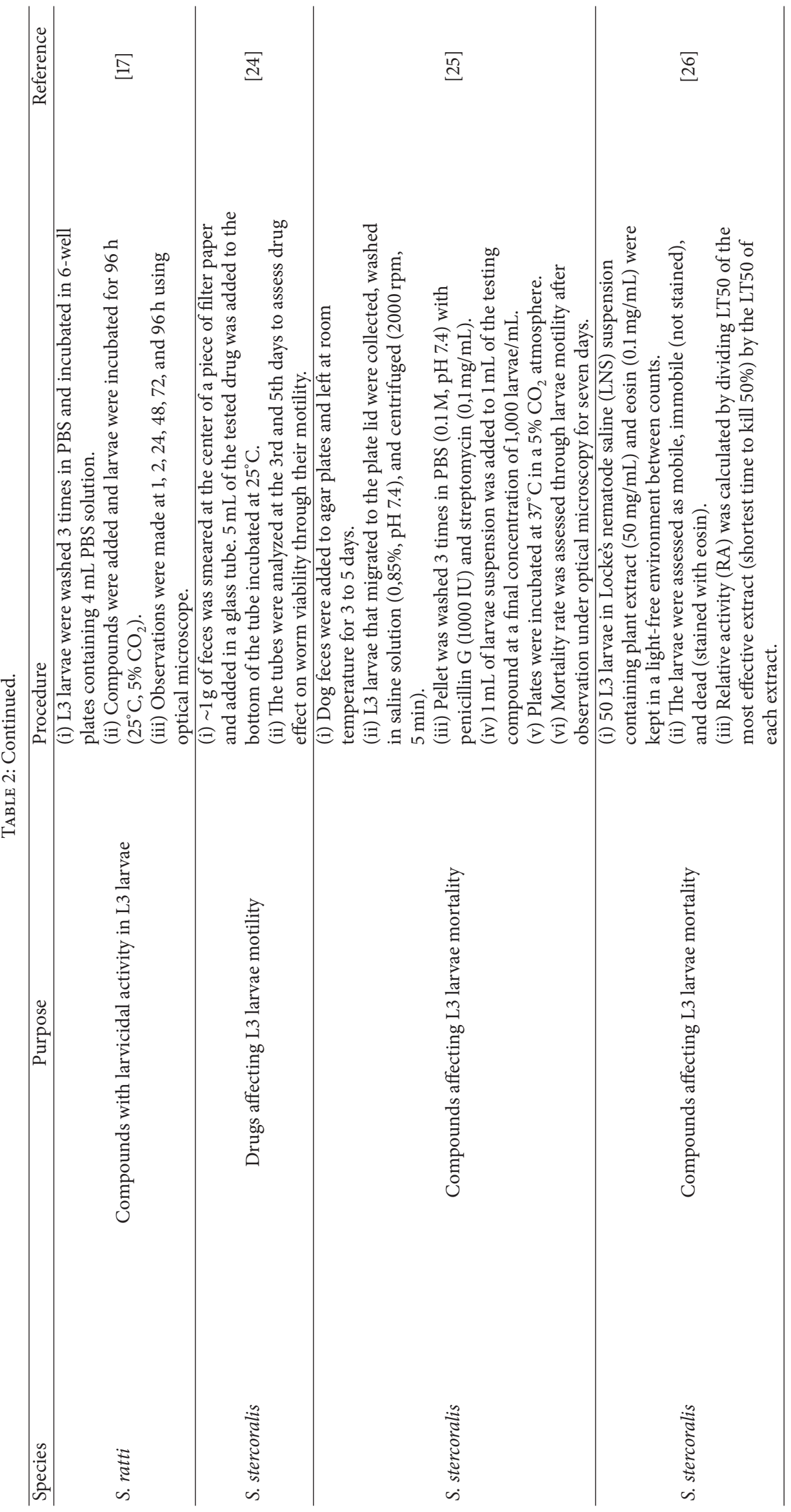




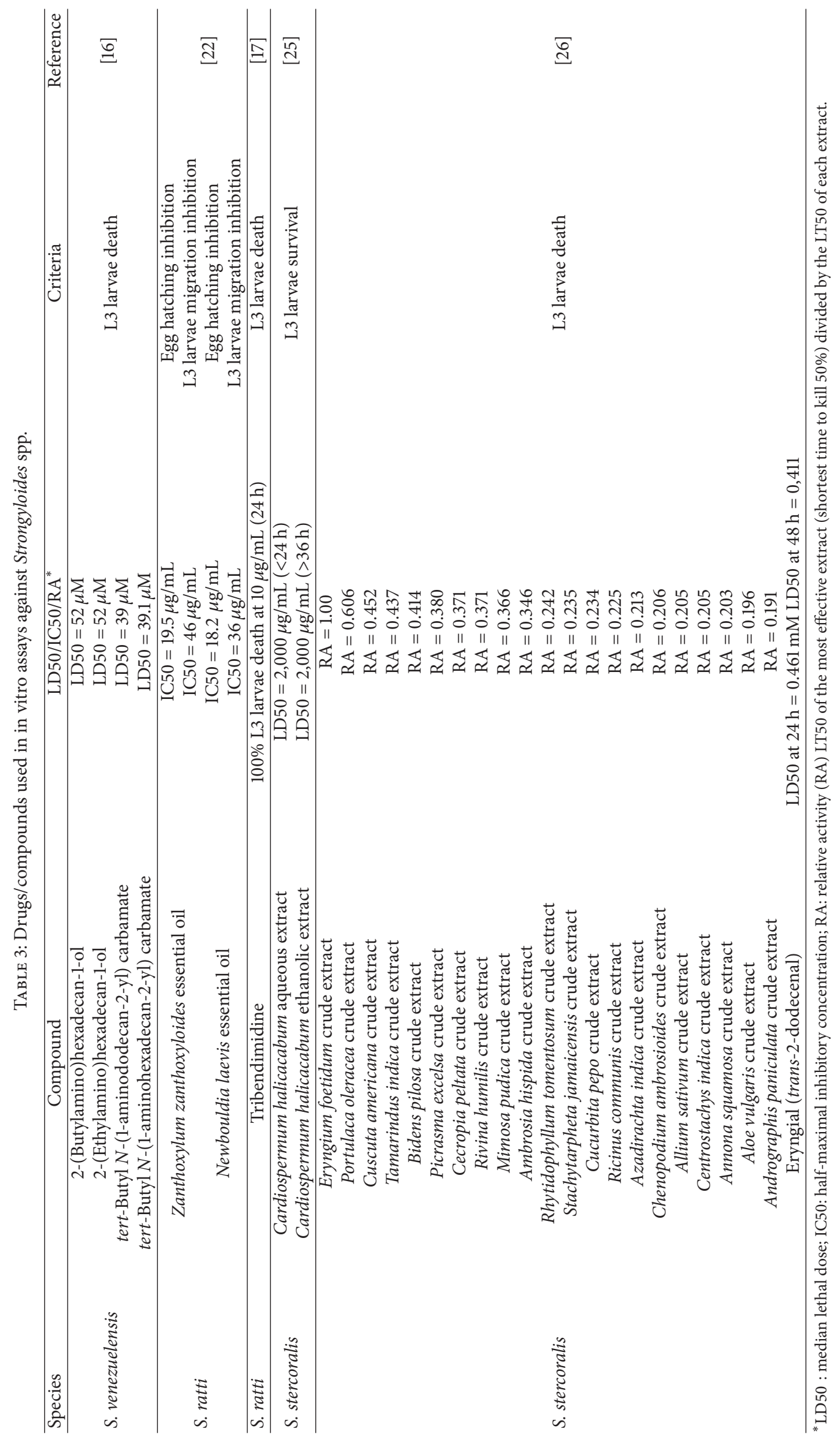




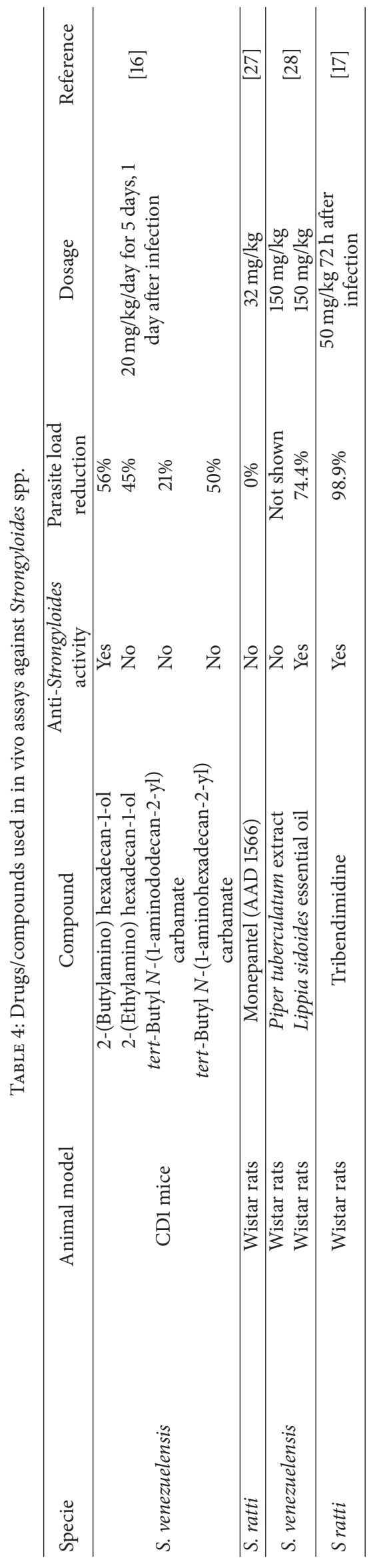


a rodent model susceptible to $S$. stercoralis infection that shows autoinfection when experimentally immunosuppressed [23]. Unfortunately, using gerbils as in vivo model of infection for drug assays is still very limited; until recently, only one study has demonstrated the efficacy of ivermectin in these $S$. stercoralis-infected animals [19].

\section{Concluding Remarks}

Strongyloidiasis is a cosmopolitan neglected disease, whose complications are strongly associated with alcoholism, organ transplants, HTLV-1 virus, and immunosuppression in general [11-14]. It is important to highlight that, even with early diagnostic, problems associated with the tests sensitivity may lead to false negatives, raising a need for new diagnostic methodologies. Some diagnostic methods (mostly immunological and molecular) are under investigation and show great potential, but more studies are needed before they can be considered as alternatives to be available in the market $[6,63,67,79,81]$. Treatment is potentially difficult and unsuccessful due to ivermectin irregular cure rates and lack of consensus regarding the number of dosages and amount of time between each administration [29-31]. New drug research is a challenge since $S$. stercoralis does not infect the most commonly used laboratory models, Mus musculus and Rattus norvegicus [98]. Using S. ratti and S. venezuelensis has represented an important alternative in this area; however, self-healing and lack of standardized methods used in these assays seem to limit the number of alternative therapy studies over the years $[10,97,98,100]$.

In this review, we pointed out the great need of strongyloidiasis early diagnosis and some promising new diagnostic methods that are being under investigation. Besides, we summarized different protocols used in new drug research and which compounds have been tested both in vitro and in vivo, in an attempt to shed some light on preclinical research directed towards the discovery of novel anti-Strongyloides candidates.

\section{Competing Interests}

The authors declare that there are no competing interests related to the publication of this paper.

\section{References}

[1] S. Puthiyakunnon, S. Boddu, Y. Li et al., "Strongyloidiasisan insight into its global prevalence and management," PLoS Neglected Tropical Diseases, vol. 8, no. 8, Article ID e3018, 2014.

[2] H. J. Dawkins and D. I. Grove, "Attempts to establish infections with Strongyloides stercoralis in mice and other laboratory animals," Journal of Helminthology, vol. 56, no. 1, pp. 23-26, 1982.

[3] M. Beknazarova, H. Whiley, and K. Ross, "Strongyloidiasis: a disease of socioeconomic disadvantage," International Journal of Environmental Research and Public Health, vol. 13, no. 5, article 517, 2016.

[4] A. L. R. Gonçalves, K. C. L. de Araújo, E. F. G. Carvalho, M. T. Ueta, and J. M. Costa-Cruz, "Specific IgG and immune complex responses to parthenogenetic females and eggs of nematode Strongyloides venezuelensis for the diagnosis of immunosuppression in infected rats," Journal of Helminthology, vol. 90, no. 3, pp. 342-346, 2015.

[5] D. R. Herbert, J. J. Lee, N. A. Lee, T. J. Nolan, G. A. Schad, and D. Abraham, "Role of IL-5 in innate and adaptive immunity to larval Strongyloides stercoralis in mice," The Journal of Immunology, vol. 165, no. 8, pp. 4544-4551, 2000.

[6] M. Boscolo, M. Gobbo, W. Mantovani et al., "Evaluation of an indirect immunofluorescence assay for strongyloidiasis as a tool for diagnosis and follow-up," Clinical and Vaccine Immunology, vol. 14, no. 2, pp. 129-133, 2007.

[7] L. A. Chaves, A. L. R. Gonçalves, F. M. Paula et al., "Comparison of parasitological, immunological and molecular methods for evaluation of fecal samples of immunosuppressed rats experimentally infected with Strongyloides venezuelensis," Parasitology, vol. 142, no. 14, pp. 1715-1721, 2015.

[8] J. Gomez-Junyent, D. Paredes-Zapata, E. R. de Las Parras et al., "Real-time polymerase chain reaction in stool detects transmission of Strongyloides stercoralis from an infected donor to solid organ transplant recipients," The American Journal of Tropical Medicine and Hygiene, vol. 94, no. 4, pp. 897-899, 2016.

[9] A. L. R. Gonçalves, G. A. Machado, M. R. F. GonçalvesPires, A. Ferreira-Júnior, D. A. O. Silva, and J. M. Costa-Cruz, "Evaluation of strongyloidiasis in kennel dogs and keepers by parasitological and serological assays," Veterinary Parasitology, vol. 147, no. 1-2, pp. 132-139, 2007.

[10] D. I. Grove, C. Northern, and P. J. Heenan, "Strongyloides stercoralis infections in the muscles of mice: a model for investigating the systemic phase of strongyloidiasis," Pathology, vol. 18, no. 1, pp. 72-76, 1986.

[11] A. Alsharif, A. Sodhi, L. C. Murillo, A. S. Headley, and D. Kadaria, "Wait!!! No steroids for this asthma," American Journal of Case Reports, vol. 16, pp. 398-400, 2015.

[12] E. A. Rodriguez, T. Abraham, and F. K. Williams, "Severe strongyloidiasis with negative serology after corticosteroid treatment," American Journal of Case Reports, vol. 16, pp. 95-98, 2015.

[13] M. L. S. Silva, E. J. Inês, A. B. S. Souza et al., "Association between Strongyloides stercoralis infection and cortisol secretion in alcoholic patients," Acta Tropica, vol. 154, pp. 133-138, 2016.

[14] M. Montes, C. Sanchez, K. Verdonck et al., "Regulatory T cell expansion in HTLV-1 and strongyloidiasis co-infection is associated with reduced IL-5 responses to Strongyloides stercoralis antigen," PLoS Neglected Tropical Diseases, vol. 3, article e456, 2009.

[15] W. A. Martins, A. L. Melo, J. R. Nicoli et al., "A method of decontaminating Strongyloides venezuelensis larvae for the study of strongyloidiasis in germ-free and conventional mice," Journal of Medical Microbiology, vol. 49, no. 4, pp. 387-390, 2000.

[16] A. L. Legarda-Ceballos, J. López-Abán, E. Del Olmo et al., "In vitro and in vivo evaluation of 2-aminoalkanol and 1,2alkanediamine derivatives against Strongyloides venezuelensis," Parasites \& Vectors, vol. 9, article 364, 2016.

[17] J. Keiser, K. Thiemann, Y. Endriss, and J. Utzinger, "Strongyloides ratti: in vitro and in vivo activity of tribendimidine," PLoS Neglected Tropical Diseases, vol. 2, no. 1, article e136, 2008.

[18] J. B. Lok, "Strongyloides stercoralis: a model for translational research on parasitic nematode biology," WormBook, pp. 1-18, 2007.

[19] P. Sithithaworn, Y. Fujimaki, Y. Mitsui, R. Prasanthong, W. Yutanawiboonchai, and Y. Aoki, "Efficacy of ivermectin against 
Strongyloides stercoralis infection in Jirds (Meriones unguiculatus)," Experimental Parasitology, vol. 89, no. 2, pp. 205-212, 1998.

[20] A. C. Kotze, S. Clifford, J. O'Grady, J. M. Behnke, and J. S. Mccarthy, "An in vitro larval motility assay to determine anthelmintic sensitivity for human hookworm and Strongyloides species," American Journal of Tropical Medicine and Hygiene, vol. 71, no. 5, pp. 608-616, 2004.

[21] D. R. Herbert, T. J. Nolan, G. A. Schad, S. Lustigman, and D. Abraham, "Immunoaffinity-isolated antigens induce protective immunity against larval Strongyloides stercoralis in mice," Experimental Parasitology, vol. 100, no. 2, pp. 112-120, 2002.

[22] P. A. Olounladé, E. V. B. Azando, M. S. Hounzangbé-Adoté et al., "In vitro anthelmintic activity of the essential oils of Zanthoxylum zanthoxyloides and Newbouldia laevis against Strongyloides ratti," Parasitology Research, vol. 110, no. 4, pp. 1427-1433, 2012.

[23] T. J. Nolan, Z. Megyeri, V. M. Bhopale, and G. A. Schad, "Strongyloides stercoralis: the first rodent model for uncomplicated and hyperinfective strongyloidiasis, the Mongolian Gerbil (Meriones unguiculatus)," Journal of Infectious Diseases, vol. 168, no. 6, pp. 1479-1484, 1993.

[24] P. M. Intapan, T. K. Prasongdee, P. Laummaunwai, K. Sawanyawisuth, S. Singthong, and W. Maleewong, "Short report: a modified filter paper culture technique for screening of Strongyloides stercoralis ivermectin sensitivity in clinical specimens," American Journal of Tropical Medicine and Hygiene, vol. 75, no. 3, pp. 563-564, 2006.

[25] T. Boonmars, W. Khunkitti, P. Sithithaworn, and Y. Fujimaki, "In vitro antiparasitic activity of extracts of Cardiospermum halicacabum against third-stage larvae of Strongyloides stercoralis," Parasitology Research, vol. 97, no. 5, pp. 417-419, 2005.

[26] W. M. Forbes, W. A. Gallimore, A. Mansingh, P. B. Reese, and R. D. Robinson, "Eryngial (trans-2-dodecenal), a bioactive compound from Eryngium foetidum: its identification, chemical isolation, characterization and comparison with ivermectin in vitro," Parasitology, vol. 141, no. 2, pp. 269-278, 2014.

[27] L. Tritten, A. Silbereisen, and J. Keiser, "In vitro and in vivo efficacy of monepantel (AAD 1566) against laboratory models of human intestinal nematode infections," PLoS Neglected Tropical Diseases, vol. 5, no. 12, Article ID e1457, 2011.

[28] C. O. Carvalho, A. C. S. Chagas, F. Cotinguiba et al., "The anthelmintic effect of plant extracts on Haemonchus contortus and Strongyloides venezuelensis," Veterinary Parasitology, vol. 183, no. 3-4, pp. 260-268, 2012.

[29] Z. Bisoffi, D. Buonfrate, A. Montresor et al., "Strongyloides stercoralis: a plea for action," PLoS Neglected Tropical Diseases, vol. 7, no. 5, Article ID e2214, 2013.

[30] G. Panic, U. Duthaler, B. Speich, and J. Keiser, "Repurposing drugs for the treatment and control of helminth infections," International Journal for Parasitology: Drugs and Drug Resistance, vol. 4, no. 3, pp. 185-200, 2014.

[31] V. Luvira, D. Watthanakulpanich, and P. Pittisuttithum, "Management of Strongyloides stercoralis: a puzzling parasite," International Health, vol. 6, no. 4, pp. 273-281, 2014.

[32] D. M. Stewart, R. Ramanathan, S. Mahanty, D. P. Fedorko, J. E. Janik, and J. C. Morris, "Disseminated Strongyloides stercoralis infection in HTLV-1-associated adult T-cell leukemia/lymphoma," Acta Haematologica, vol. 126, no. 2, pp. 63-67, 2011.

[33] P. R. S. Lagacé-Wiens and G. K. M. Harding, "A Canadian immigrant with coinfection of Strongyloides stercoralis and human T-lymphotropic virus 1," CMAJ, vol. 177, no. 5, pp. 451453, 2007.

[34] L. Ratner, C. Grant, B. Zimmerman et al., "Effect of treatment of Strongyloides infection on HTLV-1 expression in a patient with adult T-cell leukemia," American Journal of Hematology, vol. 82, no. 10, pp. 929-931, 2007.

[35] S. Janssen, E. G. Rossatanga, S. Jurriaans, I. J. M. ten Berge, and M. P. Grobusch, "Triple infection with HIV-1, HTLV-1 and Strongyloides stercoralis, rendering $\mathrm{CD} 4^{+} \mathrm{T}$-cell counts a misleading entity," Antiviral Therapy, vol. 18, no. 7, pp. 949-951, 2013.

[36] P. Hindy, R. Parvin, K. Hanna, and F. Gress, "Strongyloidiasis presenting as duodenal obstruction in a patient infected with human T-cell lymphotropic virus type 1," Gastrointestinal Endoscopy, vol. 74, no. 2, pp. 439-441, 2011.

[37] T. Kinjo, D. Nabeya, H. Nakamura et al., "Acute respiratory distress syndrome due to Strongyloides stercoralis infection in a patient with cervical cancer," Internal Medicine, vol. 54, no. 1, pp. 83-87, 2015.

[38] J. E. Weatherhead and R. Mejia, "Immune response to infection with Strongyloides stercoralis in patients with infection and hyperinfection," Current Tropical Medicine Reports, vol. 1, no. 4, pp. 229-233, 2014.

[39] M. A. F. Porto, A. Muniz, J. Oliveira Júnior, and E. M. Carvalho, "Implicações clínicas e imunológicas da associação entre o HTLV-1 e a estrongiloidíase," Revista da Sociedade Brasileira de Medicina Tropical, vol. 35, pp. 641-649, 2002.

[40] E. B. Kia, H. R. Rahimi, H. Mirhendi et al., "A case of fatal strongyloidiasis in a patient with chronic lymphocytic leukemia and molecular characterization of the isolate," Korean Journal of Parasitology, vol. 46, no. 4, pp. 261-263, 2008.

[41] M. P. Zago-Gomes, K. F. Aikawa, S. F. Perazzio, C. S. Gonçalves, and F. E. L. Pereira, "Prevalence of intestinal nematodes in alcoholic patients," Revista da Sociedade Brasileira de Medicina Tropical, vol. 35, no. 6, pp. 571-574, 2002.

[42] F. A. Abanyie, E. B. Gray, K. W. Delli Carpini et al., "Donorderived strongyloides stercoralis infection in solid organ transplant recipients in the United States, 2009-2013," American Journal of Transplantation, vol. 15, no. 5, pp. 1369-1375, 2015.

[43] B. A. Abdalhamid, A. N. A. M. Al Abadi, M. I. Al Saghier, A. A. Joudeh, M. A. Shorman, and S. S. Amr, "Strongyloides stercoralis infection in kidney transplant recipients," Saudi Journal of Kidney Diseases and Transplantation, vol. 26, no. 1, pp. 98-102, 2015.

[44] R. Agarwala, J. Wasielewski, and B. Biman, "Pulmonary strongyloidiasis following renal transplantation without travel to an endemic area," Oxford Medical Case Reports, vol. 2014, no. 4, pp. 83-85, 2014.

[45] C. Arango, C. Arango, and C. Seas, "Images in clinical tropical medicine: a 29-year-old renal transplant recipient with acute respiratory failure," American Journal of Tropical Medicine and Hygiene, vol. 86, no. 6, pp. 911-912, 2012.

[46] M. V. Batista, L. C. Pierrotti, E. Abdala et al., "Endemic and opportunistic infections in Brazilian solid organ transplant recipients," Tropical Medicine and International Health, vol. 16, no. 9, pp. 1134-1142, 2011.

[47] L. O. Coster, "Parasitic infections in solid organ transplant recipients," Infectious Disease Clinics of North America, vol. 27, no. 2, pp. 395-427, 2013.

[48] C. J. A. Ferreira, D. A. da Silva, P. H. Almeida et al., "Fatal disseminated strongyloidiasis after kidney transplantation," 
Revista da Sociedade Brasileira de Medicina Tropical, vol. 45, no. 5, pp. 652-654, 2012.

[49] K. W. Hamilton, P. L. Abt, M. A. Rosenbach et al., "Donorderived Strongyloides stercoralis infections in renal transplant recipients," Transplantation, vol. 91, no. 9, pp. 1019-1024, 2011.

[50] C. N. Hsu, S. H. Tseng, S. W. Chang, and Y. Chen, "Strongyloides stercoralis infection in an intestinal transplant recipient," Transplant Infectious Disease, vol. 15, no. 4, pp. E139-E143, 2013.

[51] A. P. Iori, A. Ferretti, G. Gentile et al., "Strongyloides stercoralis infection in allogeneic stem cell transplant: a case report and review of the literature," Transplant Infectious Disease, vol. 16, no. 4, pp. 625-630, 2014.

[52] H. Issa, M. A. Aljama, and A. H. Al-Salem, "Strongyloides stercoralis hyperinfection in a post-renal transplant patient," Clinical and Experimental Gastroenterology, vol. 4, no. 1, pp. 269-271, 2011.

[53] I. Izquierdo, J. Briones, R. Lluch, C. Arqueros, and R. Martino, "Fatal Strongyloides hyperinfection complicating a gramnegative sepsis after allogeneic stem cell transplantation: a case report and review of the literature," Case Reports in Hematology, vol. 2013, Article ID 860976, 5 pages, 2013.

[54] M. S. Khuroo, "Hyperinfection strongyloidiasis in renal transplant recipients," BMJ Case Reports, 2014.

[55] M. Le, K. Ravin, A. Hasan et al., "Single donor-derived strongyloidiasis in three solid organ transplant recipients: case series and review of the literature," American Journal of Transplantation, vol. 14, no. 5, pp. 1199-1206, 2014.

[56] V. Pochineni, D. Lal, S. Hasnayen, and E. Restrepo, "Fatal Strongyloides hyperinfection syndrome in an immunocompromised patient," American Journal of Case Reports, vol. 16, pp. 603-605, 2015.

[57] B. Chokkalingam Mani, M. Mathur, H. Clauss et al., "Strongyloides stercoralis and organ transplantation," Case Reports in Transplantation, vol. 2013, Article ID 549038, 6 pages, 2013.

[58] V. Luvira, K. Trakulhun, M. Mungthin et al., "Comparative diagnosis of strongyloidiasis in immunocompromised patients," The American Journal of Tropical Medicine and Hygiene, vol. 95, no. 2, pp. 401-404, 2016.

[59] P. Steinmann, X.-N. Zhou, Z.-W. Du et al., "Tribendimidine and albendazole for treating soil-transmitted helminths, Strongyloides stercoralis and Taenia spp.: open-label randomized trial," PLoS Neglected Tropical Diseases, vol. 2, no. 10, article e322, 2008.

[60] D. Buonfrate, F. Formenti, F. Perandin, and Z. Bisoff,, "Novel approaches to the diagnosis of Strongyloides stercoralis infection," Clinical Microbiology and Infection, vol. 21, no. 6, pp. 543552, 2015.

[61] M. Montes, C. Sawhney, and N. Barros, "Strongyloides stercoralis: there but not seen," Current Opinion in Infectious Diseases, vol. 23, no. 5, pp. 500-504, 2010.

[62] M. Sharifdini, H. Mirhendi, K. Ashrafi et al., "Comparison of nested polymerase chain reaction and real-time polymerase chain reaction with parasitological methods for detection of Strongyloides stercoralis in human fecal samples," The American Journal of Tropical Medicine and Hygiene, vol. 93, no. 6, pp. 1285-1291, 2015.

[63] C. D. Ericsson, R. Steffen, A. A. Siddiqui, and S. L. Berk, "Diagnosis of Strongyloides stercoralis infection," Clinical Infectious Diseases, vol. 33, no. 7, pp. 1040-1047, 2001.

[64] T. Arakaki, M. Iwanaga, F. Kinjo, A. Saito, R. Asato, and T. Ikeshiro, "Efficacy of agar-plate culture in detection of
Strongyloides stercoralis infection," Journal of Parasitology, vol. 76, no. 3, pp. 425-428, 1990.

[65] T. Hirata, H. Nakamura, N. Kinjo et al., "Increased detection rate of Strongyloides stercoralis by repeated stool examinations using the agar plate culture method," The American Journal of Tropical Medicine and Hygiene, vol. 77, no. 4, pp. 683-684, 2007.

[66] M. Attia, K. Kamal, M. A. Fouad, M. H. Saleh, and M. Abo-Sabe, "Direct and indirect diagnosis of strongyloidiasis," Journal of the Egyptian Society of Parasitology, vol. 22, no. 1, pp. 115-119, 1992.

[67] Z. Bisoffi, D. Buonfrate, M. Sequi et al., "Diagnostic accuracy of five serologic tests for Strongyloides stercoralis infection," PLoS Neglected Tropical Diseases, vol. 8, no. 1, Article ID e2640, 2014.

[68] D. Buonfrate, M. Sequi, R. Mejia et al., "Accuracy of five serologic tests for the follow up of Strongyloides stercoralis infection," PLoS Neglected Tropical Diseases, vol. 9, no. 2, Article ID e0003491, 2015.

[69] H. T. Gonzaga, V. S. Ribeiro, N. D. Feliciano et al., "IgG avidity in differential serodiagnosis of human strongyloidiasis active infection," Immunology Letters, vol. 139, no. 1-2, pp. 87-92, 2011.

[70] M. C. Huaman, Y. Sato, J. L. Aguilar et al., "Gelatin particle indirect agglutination and enzyme-linked immunosorbent assay for diagnosis of strongyloidiasis using Strongyloides venezuelensis antigen," Transactions of the Royal Society of Tropical Medicine and Hygiene, vol. 97, no. 5, pp. 535-538, 2003.

[71] A. F. Júnior, M. R. F. Gonçalves-Pires, D. A. O. Silva, A. L. R. Gonçalves, and J. M. Costa-Cruz, "Parasitological and serological diagnosis of Strongyloides stercoralis in domesticated dogs from southeastern Brazil," Veterinary Parasitology, vol. 136, no. 2, pp. 137-145, 2006.

[72] S. Koosha, M. Fesharaki, and M. B. Rokni, "Comparison of enzyme-linked immunosorbent assay and indirect immunofluorescence assay in the diagnosis of human strongyloidiasis," Indian Journal of Gastroenterology, vol. 23, no. 6, pp. 214-216, 2004.

[73] D. M. L. Mota-Ferreira, M. D. R. F. Gonçalves-Pires, Á. F. Júnior, M. C. Sopelete, V. O. S. Abdallah, and J. M. Costa-Cruz, "Specific IgA and IgG antibodies in paired serum and breast milk samples in human strongyloidiasis," Acta Tropica, vol. 109, no. 2, pp. $103-$ 107, 2009.

[74] W. A. Page, K. Dempsey, and J. S. McCarthy, "Utility of serological follow-up of chronic strongyloidiasis after anthelminthic chemotherapy," Transactions of the Royal Society of Tropical Medicine and Hygiene, vol. 100, no. 11, pp. 1056-1062, 2006.

[75] B. J. Pak, F. Vasquez-Camargo, E. Kalinichenko et al., "Development of a rapid serological assay for the diagnosis of strongyloidiasis using a novel diffraction-based biosensor technology," PLoS Neglected Tropical Diseases, vol. 8, no. 8, Article ID e3002, 2014.

[76] Y. Sato, J. Kobayashi, and Y. Shiroma, "Serodiagnosis of strongyloidiasis. The application and significance," Revista do Instituto de Medicina Tropical de Sao Paulo, vol. 37, no. 1, pp. 35-41, 1995.

[77] L. R. Bosqui, A. L. R. Gonçalves, M. D. R. F. Gonçalves-Pires et al., "Detection of parasite-specific IgG and IgA in paired serum and saliva samples for diagnosis of human strongyloidiasis in northern Paraná state, Brazil," Acta Tropica, vol. 150, pp. 190195, 2015.

[78] E. F. G. de Carvalho, J. E. N. de Sousa, A. L. R. Gonçalves, J. P. da Cunha-Junior, and J. M. Costa-Cruz, "Immunoblotting using Strongyloides venezuelensis larvae, parthenogenetic females or eggs extracts for the diagnosis of experimentally infected immunosuppressed rats," Experimental Parasitology, vol. 157, pp. 117-123, 2015. 
[79] S. L. Becker, N. Piraisoody, S. Kramme et al., "Real-time PCR for detection of Strongyloides stercoralis in human stool samples from Côte d'Ivoire: diagnostic accuracy, inter-laboratory comparison and patterns of hookworm co-infection," Acta Tropica, vol. 150, pp. 210-217, 2015.

[80] F. M. Paula, R. B. Sitta, F. M. Malta et al., "Parasitological and molecular diagnosis in experimental Strongyloides venezuelensis infection," Revista do Instituto de Medicina Tropical de São Paulo, vol. 55, no. 2, pp. 141-143, 2013.

[81] S. L. Becker, J. K. Chatigre, J.-P. Gohou et al., "Combined stoolbased multiplex PCR and microscopy for enhanced pathogen detection in patients with persistent diarrhoea and asymptomatic controls from Côte d'Ivoire," Clinical Microbiology and Infection, vol. 21, no. 6, pp. 591.el-591.e10, 2015.

[82] P. D. Marques, F. M. Malta, D. M. C. L. Meisel et al., "Diagnosis of the strongyloid nematode Strongyloides venezuelensis in experimentally infected rats," Journal of Helminthology, vol. 90, pp. 422-427, 2016.

[83] E. Nadir, T. Grossman, P. Ciobotaro et al., "Real-time PCR for Strongyloides stercoralis-associated meningitis," Diagnostic Microbiology and Infectious Disease, vol. 84, no. 3, pp. 197-199, 2016.

[84] F. M. de Paula, F. D. M. Malta, P. D. Marques et al., "Molecular diagnosis of strongyloidiasis in tropical areas: a comparison of conventional and real-time polymerase chain reaction with parasitological methods," Memorias do Instituto Oswaldo Cruz, vol. 110, no. 2, pp. 272-274, 2015.

[85] S. A. Repetto, C. D. A. Soto, S. I. Cazorla et al., "An improved DNA isolation technique for PCR detection of Strongyloides stercoralis in stool samples," Acta Tropica, vol. 126, no. 2, pp. 110114, 2013.

[86] S. A. Repetto, P. Ruybal, M. E. Solana et al., "Comparison between PCR and larvae visualization methods for diagnosis of Strongyloides stercoralis out of endemic area: a proposed algorithm," Acta Tropica, vol. 157, pp. 169-177, 2016.

[87] J. M. Saugar, F. J. Merino, P. Martín-Rabadán et al., “Application of real-time PCR for the detection of Strongyloides spp. in clinical samples in a reference center in Spain," Acta Tropica, vol. 142, pp. 20-25, 2015.

[88] F. Schär, P. Odermatt, V. Khieu et al., "Evaluation of real-time PCR for Strongyloides stercoralis and hookworm as diagnostic tool in asymptomatic schoolchildren in Cambodia," Acta Tropica, vol. 126, no. 2, pp. 89-92, 2013.

[89] R. B. Sitta, F. M. Malta, J. R. Pinho, P. P. Chieffi, R. C. B. Gryschek, and F. M. Paula, "Conventional PCR for molecular diagnosis of human strongyloidiasis," Parasitology, vol. 141, no. 5, pp. 716-721, 2014.

[90] S. St Cyr, A. Nagpal, and M. R. I. Sohail, "Shiga toxin producing E coli bloodstream infection secondary to Strongyloides penetration through intestinal mucosa," BMJ Case Reports, vol. 2013, 2013.

[91] Y. Sultana, N. Jeoffreys, M. R. Watts, G. L. Gilbert, and R. Lee, "Real-time polymerase chain reaction for detection of Strongyloides stercoralis in stool," The American Journal of Tropical Medicine and Hygiene, vol. 88, no. 6, pp. 1048-1051, 2013.

[92] M. Z. Abdelrahman, M. Zeehaida, N. Rahmah et al., "Fatal septicemic shock associated with Strongyloides stercoralis infection in a patient with angioimmunoblastic T-cell lymphoma: a case report and literature review," Parasitology International, vol. 61, no. 3, pp. 508-511, 2012.
[93] K. Chunlertrith, A. Noiprasit, C. Kularbkaew, O. Sanpool, W. Maleewong, and P. M. Intapan, "A complicated case of strongyloidiasis presenting with intestinal lymphadenopathy obstruction: molecular identification," Southeast Asian Journal of Tropical Medicine and Public Health, vol. 46, no. 1, pp. 1-7, 2015.

[94] A. N. Seo, Y.-K. Goo, D.-I. Chung, Y. Hong, O. Kwon, and H.-I. Bae, "Comorbid gastric adenocarcinoma and gastric and duodenal Strongyloides stercoralis infection: a case report," Korean Journal of Parasitology, vol. 53, no. 1, pp. 95-99, 2015.

[95] E. J. Won, J. Jeon, Y.-I. Koh, and D. W. Ryang, "Strongyloidiasis in a diabetic patient accompanied by gastrointestinal stromal tumor: cause of eosinophilia unresponsive to steroid therapy," Korean Journal of Parasitology, vol. 53, no. 2, pp. 223-226, 2015.

[96] S. Bonne-Anneé, J. A. Hess, and D. Abraham, "Innate and adaptive immunity to the nematode Strongyloides stercoralis in a mouse model," Immunologic Research, vol. 51, no. 2-3, pp. 205214, 2011.

[97] Y. Sato and H. Toma, "Strongyloides venezuelensis infections in mice," International Journal for Parasitology, vol. 20, no. 1, pp. 57-62, 1990.

[98] G. Wertheim, "Experimental concurrent infections with Strongyloides ratti and S. venezuelensis in laboratory rats," Parasitology, vol. 61, no. 3, pp. 389-395, 1970.

[99] D. I. Grove, Strongyloidiasis: A Major Roundworm Infection of Man, Taylor \& Francis, 1989.

[100] V. M. Bhopale, G. Smith, H. E. Jordan, and G. A. Schad, "Developmental biology and migration of Strongyloides ratti in the rat," Journal of Parasitology, vol. 78, no. 5, pp. 861-868, 1992.

[101] M. Mojon, C. Saura, N. Roojee, and R. T. M. Sung, "An experimental model for therapeutic trials of anthelminthic drugs," Journal of Antimicrobial Chemotherapy, vol. 19, no. 1, pp. 73-77, 1987.

[102] C. E. Olson and E. L. Schiller, "Strongyloides ratti infections in rats. II. Effects of cortisone treatment," American Journal of Tropical Medicine and Hygiene, vol. 27, no. 3, pp. 527-531, 1978.

[103] R. E. Weesner, J. Kolinjivadi, R. A. Giannella, T. HuitgerO'Connor, and R. M. Genta, "Effect of Strongyloides ratti on small bowel function in normal and immunosuppressed host rats," Digestive Diseases and Sciences, vol. 33, no. 10, pp. 13161321, 1988.

[104] V. L. T. Mati, P. Raso, and A. L. de Melo, "Strongyloides stercoralis infection in marmosets: replication of complicated and uncomplicated human disease and parasite biology," Parasites \& Vectors, vol. 7, no. 1, article 579, 2014.

[105] P. Steinmann, X.-N. Zhou, Z.-W. Du et al., “Tribendimidine and albendazole for treating soil-transmitted helminths, Strongyloides stercoralis and Taenia spp.: open-label randomized trial," PLoS Neglected Tropical Diseases, vol. 2, no. 10, article no. e322, 2008. 

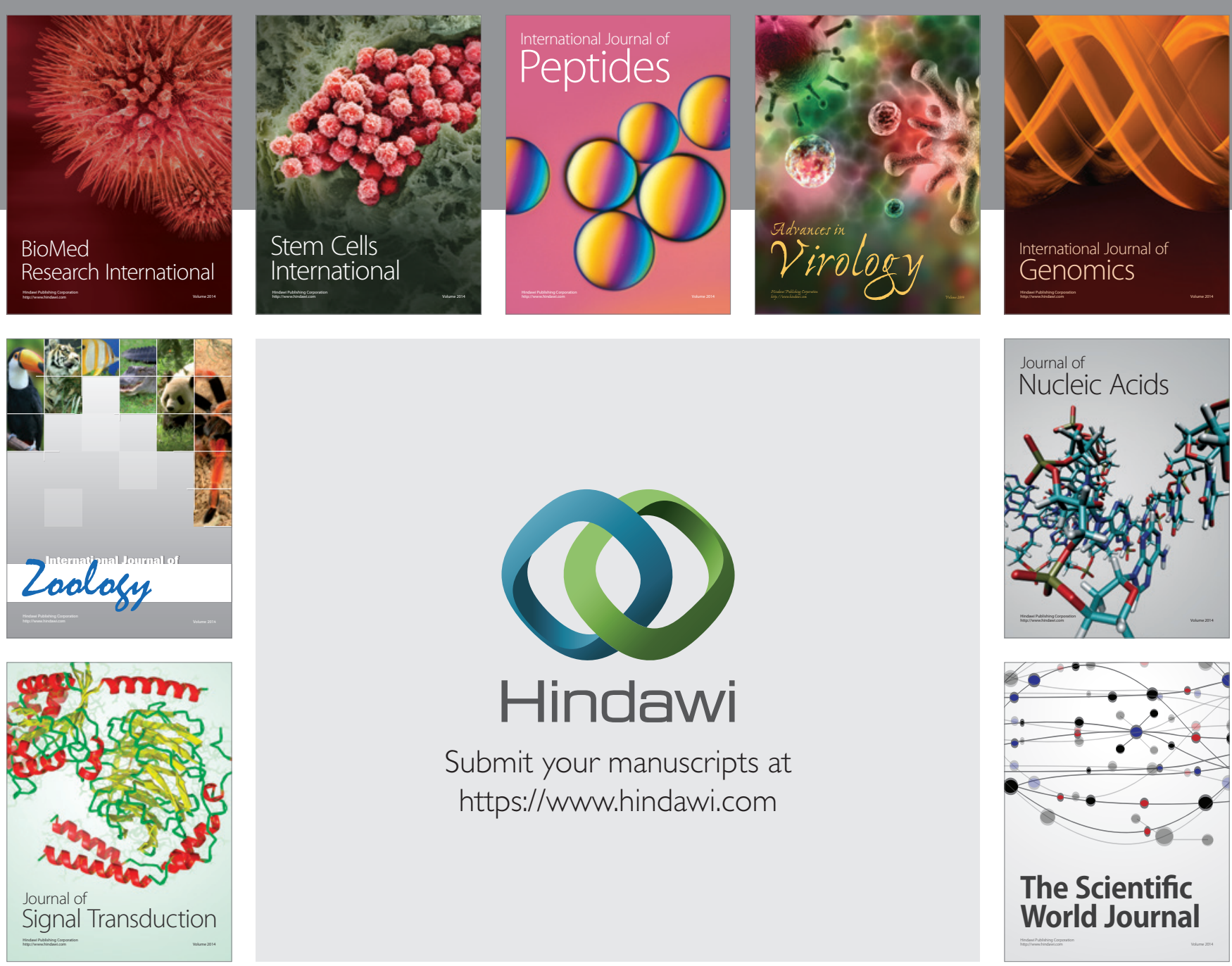

Submit your manuscripts at

https://www.hindawi.com
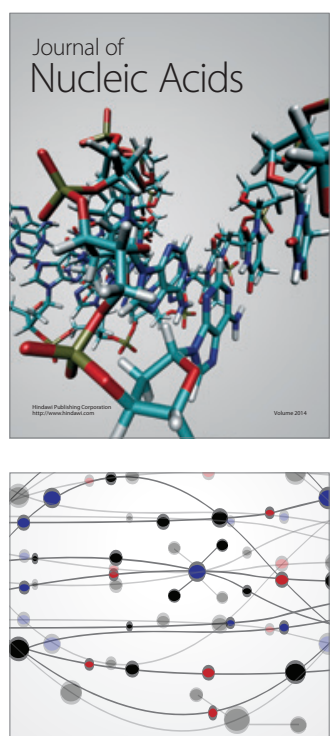

The Scientific World Journal
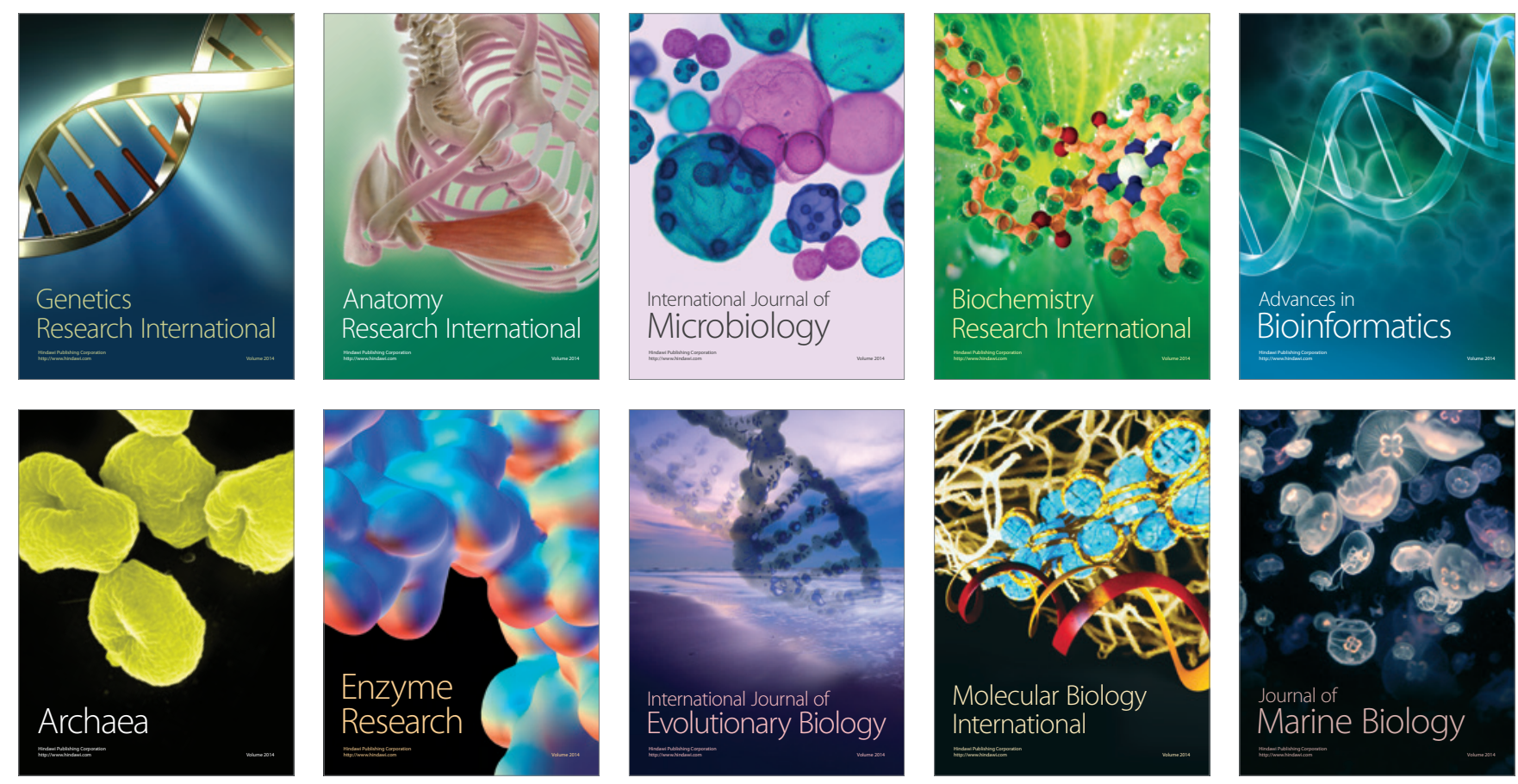